Article

\title{
Open-Ended Online Diaries: Capturing Life as It Is Narrated
}

\author{
Anne Kaun \\ Doctoral Student \\ Media and Communication Studies \\ Södertörn University \\ Sweden
}

(C) 2010 Kaun. This is an Open Access article distributed under the terms of the Creative Commons Attribution License (http://creativecommons.org/licenses/by/2.0), which permits unrestricted use, distribution, and reproduction in any medium, provided the original work is properly cited.

\begin{abstract}
Weblogs and life journals are popular forms of reflecting and reporting online about one's everyday life. In this article the author examines whether solicited online diaries can be used in qualitative research. She discusses advantages and disadvantages of the online research, diaries as a source of data, and narration as a method. The discussion is exemplified by the presentation of an online diary study conducted in two parts in the spring and autumn of 2009 with students from Tartu, Narva, and Tallinn, Estonia. This article shows the illuminating potential and richness of solicited online diaries applied in an open-ended, qualitative understanding as a way to investigate everyday life. At the same time, the main challenges are presented and discussed.
\end{abstract}

Keywords: online research, open-ended online diaries, narrative methods

Author's note: Anne Kaun is a doctoral candidate in Media and Communication Studies at Södertörn University. She is currently working on her dissertation on young adults and civic engagement in Estonia, and has published on playful public connectivity. 


\section{Introduction}

Research online is a flourishing topic within empirical research as well as theoretical reasoning. At the same time, however, the critical methodological engagement with research online is still in its developing stages. In this article, therefore, I examine the advantages and challenges of conducting research online. Within the realm of online research, one can identify a strand of research focusing on weblogs and life journals because they are popular forms of self-reporting and self-reflection (e.g., Macdonald \& Ounis, 2006; Marwick, 2008; Serfaty, 2004). Some of these sources could be thought of as (post)modern forms of diaries but shared with a broader, and in some cases not so broad, public. Analyses of those digital fingerprints by the so-called "digital natives” are increasing (Bennett, Maton, \& Kervin, 2008; Prensky, 2001).

Sociology, medical research, and psychology have counted diaries as established research data since the early 20th century, when the format of time use research was broadly established (Couldry, Livingstone, \& Markham, 2007; Gershuny \& Sullivan, 1998), but the scholarly application of diaries appears to be constrained to quantitative and strongly structured documentation or recollections of certain behaviors, habits, or feelings under particular conditions (Bolger, Davis, \& Rafaeli, 2003). There is a gap in the discussion of diary methodology when it comes to qualitative and open-ended designs focusing on subjective states and perceptions of social phenomena (Gershuny \& Sullivan, 1998). Therefore, I combine a discussion of the advantages and challenges of doing research online and using semistructured diaries as data.

The data provided in open-ended diaries are investigated as narratives constructing the participant's identity, which could be focused on certain topics or events in everyday life guided by instructions. Diaries give the researcher the possibility of "getting close" to the participants (Burgess, 1999). At the same time, room is left to the diarists, who are not constrained by a certain interview situation, focus group discussions, or participatory observation by the researcher. In the article I therefore examine how those possibilities can be used in qualitative research and what the limitations of the diaries as data are.

In the following pages, I will discuss online research, dairies as a source of data, and narration as a method and an object of inquiry. I illustrate the general methodological discussion with an online diary study, which was conducted in two waves during the spring and autumn of 2009 in Estonia; the study was dedicated to the participants' perception of the public and the private being anchored in their everyday life. The participants were students from Tallinn, Narva, and Tartu with different ethnic backgrounds. The rather open instructions led to a broad variety in the diary production portion of the study. A postevaluation of the participants is included in the discussion of online diaries as data.

\section{Background}

I explored the diary method within the framework of a study entitled The Potential Citizen: Young Adults Exploring Publics and Politics, with the aim of understanding and examining young adults' perceptions of what the public and political sphere actually mean for them as opposed to the private sphere. The project examined the specific implications of young adults engaging with a common public and politics in the consumer-oriented, postcommunist society of Estonia. What do young people between the ages of 18 and 29 perceive as important public issues, and what does this tell us about newly evolving possibilities of engagement (for example, 
in online environments)? Do we need to redefine the traditional understanding of the public and the political to include those young adult, "potential” citizens who are growing up in a digital world?

Habermas (1981) suggested that communicative action is basic to the realm of everyday social life, which he called the lifeworld (Lebenswelt). Here social relations are guided and sustained by mutual understanding. Reality in everyday life is constructed by intersubjective common sense. At the same time, everyday life originates in the thoughts and actions of "ordinary" people (Berger \& Luckmann, 1991). Connections with a common public are based in everyday life, in a stream of everyday routines, interactions, and events that are taken for granted. Rather than looking at the outstanding, extraordinary situation of election and party campaign times, I am instead looking at public connections in everyday structures (Couldry et al., 2007). Talks and discussions with family and friends, and the reasoning about personal issues are triggered by public discourses; on the other hand, personal issues that are reflected on a more abstract level could be drawn into the public realm.

To approach these rather abstract and theoretical questions, I chose diaries as the data and narration as the method. The diaries were placed online to make the diary writing process as convenient as possible for the participants and to extend the possibilities of writing the diary (e.g., to add hyperlinks, upload pictures, or change the visual appearance of the diary).

\section{Literature review}

\section{Research online: state of the art}

Internet research could be described as being in its teenage years; that is, it is experiencing rapid changes and growth while growing increasingly independent. At the same time, it is still in the phase of self-discovery and self-definition. Sudweeks and Simoff (1999), therefore, stressed that "a modern Internet research methodology should take into account rapidly changing technology, social norms and communication behaviour” (p. 30).

Online research has several advantages and disadvantages. The online environment offers the potential to observe new social phenomena, such as the behavior of very large groups (e.g., Facebook users). In addition to this behavior, the researcher is provided with a widespread geographical access to participants. Furthermore, online research has rather low monetary costs and a low time investment compared to traditional forms of data collection like large-scale transnational surveys using paper-and-pencil questionnaires, telephone interviews, face-to-face interviews, or focus groups (Kraut, Olson, Banaji, Bruckmann, Cohen, \& Couper, 2004). By using the technical infrastructure of the Internet as the connecting medium over time and distance, research can become not only more efficient but potentially more informative. As such, researchers can now reach new groups of informants more easily (for example, young adults being considered as “digital natives” [Prensky, 2001, p. 1]).

Kraut et al. (2004) have identified two main challenges of online research. There are ethical challenges, such as the treatment of research participants and data security of material collected online. On the other hand, the authors discuss the quality of data as a challenge in terms of contacting and recruiting participants. The Internet has a myriad of possibilities, but a crude application of former standards and ethical guidelines is highly questionable. Therefore, a development of distinct and adjusted standards for online research is needed. Furthermore, several researchers have underlined the importance of e-research (Fry \& Schroeder, 2009; Jankowski, 2009) and great amounts of taxpayers' money is invested in developing new online 
research data processing and archiving possibilities (Halfpenny, Procter, Lin, \& Voss, 2009). The discussion focuses mainly on how to improve the networking options for international research teams (Genoni, Merrick, \& Willson, 2009) or on using preexisting data processed and stored in the World Wide Web (Fuchs, 2009; Kendall, 1999; Schneider, Foot, \& Wouters, 2009; Siibak, 2009; Witmer, Colman, \& Katzman, 1999).

Online ethnography seems to be a rising star in the research sky, but it is also mainly focused on preexisting data and is mainly understood as following certain groups in their online environments (Sade-Beck, 2009). An intense discussion on how to employ online possibilities for gaining solicited information is currently missing. Some textbooks mention the option of applying online versions of traditional data collection tools like online surveys and the e-mail distribution of questionnaires (Bolger, Davis et al., 2003; Sade-Beck, 2009), but a discussion of advancing specific qualitative tools developed for the online world is almost completely lacking.

\section{Ethical aspects of qualitative online research}

The online environment could be described as a place of transgression of cultural rules, a place where boundaries and taboos are broken. This characteristic might raise questions of selfregulation and responsibility for the researcher working with online methods (Kanuka \& Anderson, 2007). Participants might develop a feeling of anonymity and expose information, which he or she would not give in other contexts. Especially in research methods that use preexisting material, the basic principles of anonymity and informed consent are challenged because the researcher could always argue that the individuals are exposing themselves voluntarily in a certain part of the public sphere (Kanuka \& Anderson, 2007; Serfaty, 2004). The Association of Internet Researchers has clearly pointed out that observers

seeking informed consent need to make clear to their subjects how material about them and/or from them will be used-i.e., the specific uses of material and how their identities will be protected are part of what subjects are informed about and asked to consent to. (Ess, 2002, cited in Serfaty, 2004, p. 10)

How far these types of questions need to be reflected on is specific to the research context. In the case of the solicited open-ended diaries that are the focus of this study, I asked the participants to provide informed consent by creating an account for the online wiki.

Another challenge in terms of ethical standards for online research is the question of data security. In the case of solicited material, the researchers must make sure that the data produced online are stored and secured as well as inaccessible to third parties. In my case, I used PBworks to provide closed wikis as a platform for the online diaries. Before I set up the diaries, I studied the security statements of PBworks and consulted third-party reports about these operational procedures.

In general, ethical standards for research are challenged in online environments because boundaries between public and private are blurred; however, the participation in online studies is not more risky than the participation in any of the offline counterparts. Risks should be reviewed and questioned carefully for the specific research project (Kraut et al., 2004; Sudweeks \& Simoff, 1999). 


\section{Diary designs and typologies: strengths and weaknesses}

Nonsolicited and preexisting dairies have a rather long tradition, especially in literary terms (Serfaty, 2004). With Philippe Lejeune's work on diaries, a new and intensified interest in (nonsolicited) diaries and diary writers appeared in the 1980s. He dedicated an immense part of his research to privately written unpublished diaries and to the questions of where the diary comes from and why people keep diaries. Lejeune (2006/2009) systematically traced the diary back in history and described the origin of it in commerce. The initial purpose of keeping a diary was to organize one's work life; however, in time, it transformed from spiritual reasoning about the relationship between man and God to a dialogic relationship between the diarist and an imaginary addressee that was crystallized in the heading, "Dear diary" (Lejeune, 2004/2009, 2007/2009). In 1999 and 2000, Lejeune extended his research to the Internet and studied the phenomenon of online diaries, which had just appeared in the French-speaking world. Besides studying the diaries as such, he asked diarists about their motivation in keeping a diary and about the relationship they had with their diaries. His approach to dairies as data is different in character to mine, however, as I do not analyze preexisting journals or weblogs but employ solicited diaries being partly structured by open instructions.

In turn, the scholarly application of solicited diaries can be traced back to the early time-use diaries that were broadly used in the 1920s (Gershuny \& Sullivan, 1998), but even if one speaks of a broad application of diaries, at least in a strongly structured format, theoretical reasoning and methodological discussions are missing. A search of any textbook on qualitative research methods reveals this argument. If diaries are mentioned at all, they are discussed as supplementing in-depth interviews or focus group discussions and are used by researchers to organize field notes (e.g., Bryman \& Burgess 1999; Burgess, 1998; Banister, Burman, Parker, Taylor, \& Tindall, 1994; Ritchie \& Lewis, 2003). However, open-ended, solicited diaries, as opposed to preexisting diaries, can be of great use in capturing subjective states and perceptions of participants.

Bolger et al. (2003), by focusing on quantitative, structured forms of diaries, have made a distinction between time-based diaries and event-based diaries. Time-based diaries follow fixed or variable schedules defined by the researcher on the basis of research questions and aims. Event-based diaries are kept after or during certain instances take place; for example, after a great loss of close relatives. They are especially appropriate for capturing rare and/or isolated processes. Furthermore, the authors distinguish between different analytical foci for working with diaries. For one, diaries can reveal the difference between people's narrations as aggregated material. Additionally, the focus could be on intrapersonal or interpersonal developments over time (Bolger et al., 2003). The periodical form of diaries was of special interest for my study because certain narrated subjects are constantly reappearing in the diary entries and also across diaries over time.

Disadvantages of diaries include symptoms of fatigue and high dropout rates because they involve a rather high burden for the participants. The strong dedication that is needed among the participants can also lead to "less in-depth reporting of a phenomenon at each time of measurement” (Bolger et al., 2003, p. 592). Certain phenomena revealed in the diaries could be triggered and produced by the mere fact that participants are under observation and feel the need to produce valuable content. How the researcher relates to the issue must be decided on a caseby-case basis. In the case of my study, I was interested in the participants' perceptions of, and their relationship with, the public. The production and adaptation of the diary in a certain, individual way was understood as an expression of the relationship with the public itself. In addition, the everyday life unfolding in the diaries was of great importance for the method chosen in my study. 


\section{Methodology}

\section{Solicited open-ended diaries: life as it is narrated}

Booth (1999) has argued that narratives as a research method have experienced a revival since the mid-1990s due to the continuous importance of the Chicago School as well as to feminist and critical race theory scholarship. Narrative methods are understood as ways of making heard the voices of the oppressed and subaltern; that is, the voices of those normally excluded from academic discourse. The second argument for narrative methods that Booth presented is the overcoming of subordination of people's lives to the quest for generalization by researchers. Narratives are able to capture personal experiences through the imagination of the reader. Stories being told also encompass the emotional experiences of the storyteller, which are normally suppressed by objective, abstract methods.

The diaries produced in my study are understood as encompassing meaningful units that organize and structure reflections and experiences of the participants in stories or narrations. As Moen (2006) has argued, narratives are both methods and phenomena of inquiry and are treated as such in my case. Moen, with a clear foundation in Ricoeur, has focused on three main underpinnings of narratives as research methods. First, all experiences are organized within narratives. Those narratives are told between individuals, but they are also produced as introspectives. Through storytelling, one assigns meaning to certain experiences or aspects of experiences. Second, narratives being told depend on the social past and present of the storyteller as well as the addressees of the story. Stories are not isolatable single structures but identity constructions that are continuously negotiated and revised. Third, narratives are multivoiced; namely, they are shaped by the individual experiences, knowledge, values, and feelings. At the same time they are collective stories influenced by the addressees and the "cultural, historical and institutional settings in which they occur" (Moen, 2006, p. 61). Narratives are connecting points for the individual with its social surroundings. In this connection process, a multitude of voices are included and related to each other in the personal stories being told.

Narrations in diaries mark at the same time a life process rather than finished life narratives, "and as such they are ... part of the practice of narrating and understanding what life means" (Rak, 2009, p. 19). Because the aim of the present study is to understand the connection of the participants with a common public, narrations in diaries seem appropriate as a method and phenomenon of inquiry. Hence, the narrations of the diarist give me the chance to study the participants' relation to a common public in development over time as well as relate them to the social and cultural context.

In contrast to other open-ended forms with the aim of capturing narrated identities, for example, life story telling (Chaitin, 2004), diaries have the potential to give participants much more space for reasoning and reflection to build identity narratives. At the same time, participants can develop an individual relationship with the diary and the imagined readership. Furthermore, they can decide whether they are in the mood for writing or not. Also, I had the chance to guide their reflections to a certain extent through open formulated instructions. During the writing process I did not interfere. I commented on entries only if participants directly asked for technical advice or content-related explanations. The main goal of the study was to inspire and investigate narrated parts of the everyday life of young adults in Estonia, with an emphasis on perceptions of public, politics, and media (which I made explicit in the instructions). After the postevaluation (in the form of a structured, standardized questionnaire and additional open-ended discussions), the 
suggestion to write about a topic of the week was added. Some participants expressed difficulties in coming up with a topic, which has already been described as a limitation of diaries in general (Bolger et al., 2003).

\section{Data collection}

To grasp the phenomena of everyday life, a method is appropriate if it gets close to participants but leaves them enough space for personal reflections. Diaries as a source of data give researchers the ability to apply narrations as a method to grasp forms of identity and meaning construction; in my case, within the broad frame of public and public connectedness. The participants were asked to elaborate on issues and topics that were important in their everyday lives: topics they discuss with their friends and family, those that appear in the media, or those about which they actively search for information. The rather openly formulated instructions ${ }^{1}$ on content caused a high level of variation in the diaries.

The study with 20 Estonian participants (12 females and 8 males) was carried out in two waves from March until May and September until December 2009. The participants were all students aged between 19 and 27. Of these, 17 identified themselves as Estonian and 3 as Russian or Ukrainian. Two described themselves as having regular employment; the other 18 self-identified as students. I contacted the diarists through mailing lists and seminar presentations in Tallinn, Tartu, and Narva. Initial contact with the participants was thus established in both online and offline situations. In that sense I, as the investigating subject, was visible to the participants (Rautio, 2009). During the initial meetings or e-mail exchanges all participants were informed about the purpose of the study, and confidentiality was guaranteed throughout the whole project. By creating an account through the online wiki, they confirmed informed consent. Because of the study Potential Citizens: Young Adults Exploring Publics and Politics, the diarists in the present study were chosen based on their age (18 to 29 years), educational background (current students or obtained at least a bachelor degree at a college or university) and ethnic background. ${ }^{2}$ The diaries could be kept in Estonian, Russian, or English according to the participants' preferences. Diaries written in Estonian or Russian were translated afterward. After the period of 8 weeks, the online diaries were copied and deleted from the platform.

\section{Technical aspects of the study}

The diaries were kept in closed online wikis or weblogs. Wikis provide the opportunity to share content online. Diarists had the opportunity to create content pages and to edit them, as well as the option to share files with the author. PBwikis ${ }^{3}$ were used as tools, which offered the possibility to create closed wikis that were accessible only to the diarist and the researcher.

PBworks, the company providing PBwikis, states in its security statement that it uses the highest available technological standard to secure user data. Company policy forbids employees from accessing private data. At the same time, PBworks claims no ownership of the data. ${ }^{4}$ For the creation of a free wiki, data such as name and e-mail address must be provided. Diarists created an account after invitation by the researcher by entering a user name and e-mail address (which had already been used in the invitation mail). This form of data collection had several advantages; for example, I received notifications by e-mail if content was added or changed and thus got a useful overview of activities within the diary. In addition, participants could freely adjust the design and structure of the diary to their needs. Furthermore, I was able to communicate with the 
diarist through the comment function provided in the wiki; in other words, I could directly intervene if they had questions or difficulties with writing the diary. In any event, they had the opportunity to choose when and for how long they wrote their entries.

The online diary writing was fruitful in the case of the study because the target group was highly Internet literate and showed high rates of Internet usage; Estonia claims to be an e-state (eEstonia) and was the first country to carry out online elections in Europe (Government of the Republic of Estonia, 2009). ${ }^{5}$ In 2007, 98.3\% of young people between 15 and 19 and $94.0 \%$ of those between 20 and 29 said they used the Internet regularly in the previous 6 months. However, one has to keep in mind that there still is an ethnic division between Russian and Estonian speakers; $52.8 \%$ of ethnic Estonians used the Internet over the 6 month period compared to only $36.6 \%$ of the non-Estonian population (Vilhalemm, 2008).

Because of the potential digital divide within the group of interest, the application of online diaries in qualitative studies must be well thought out and justified, similar to any other method. The still existing digital divide might have constrained the target groups included in the research project. One researcher noted this problem of defining the research population for online studies because traditional parameters are not applicable (Jones, 1999). All of these challenges have to be taken into consideration when constructing the research design, but if the aim of the study and the contextual setting allows, or even asks, for the application of open-ended, solicited, online diaries, the researcher is provided with rich, vivid, and illuminating material.

\section{Analysis}

\section{Self-reflexivity and the relationship with the diary}

The narrations constructed in the diaries revealed how the participants interpreted the diary genre and what they thought should be included in, and counted as, diaries. As such, the variation between different interpretations was rather broad. There was, for example, Anu, ${ }^{6}$ who wrote in the diary in the same way as she wrote her personal diary in her personal life, on a daily basis. Others applied a more weblog-oriented style. Jaan, for example, published his diary for the study partly on his homepage as a weblog:

This blog will be published both in my site and the PBWiki, so I will probably add links to some items in my homepage in future as well. (Jaan)

Reflexivity about the diary writing process was a recurring feature in numerous diaries. The authors indicated their uncertainty about what to write and how to begin the diary, but they also stressed the exciting point of taking part in the study.

Today on 18th of March I started something interesting for me. I started participating in this wiki. I thought it would be an interesting experience for me to get to know the opportunities a wiki has to offer. (Eliisabeth)

At the same time, many participants developed rather close ties to their diaries. Kristjan, in particular, explicitly talked of his appreciation for finally being able to express his opinions in the diary. 
My diary has been dealing overwhelmingly with the media issues. I'll try to have it more "diary-like" later on, but I just cannot proceed without writing a little bit about Reporter. I'll use this space here to vent my anger and disgust at what they are airing on television and which sadly appears to be quite popular as well. (Kristjan)

Besides functioning as a way for individuals to express themselves, the diaries revealed "ordinary" strategies like weather talk among the participants as well. As Barthes (1972) put it, "Talking about weather makes it possible for discourse to exist without saying anything" (cited in Serfaty, 2004, p. 47) and therewith the weather holds a pride of place.

I begin to write my wiki during a day, which is weather-wise reminding more of Christmas time than spring. Related to it I heard from my colleague the very frustrating news that the snow won't melt before the end of April. (Anu)

\section{Diary as a genre and the relationship with the implied reader}

Diarists also interpreted the expectations of the reader, the imagined audience, while writing. How and what the diarists presented in their entries, the narrations, represented their understanding of the diary genre, which in the modern understanding is kept privately and as a rather intimate form of expression. Because I moved the diary into a blurred space of private/public distinction - that is, the Internet - the diary also served a different function. The diary genre is thus partly relegated to a premodern understanding, where diaries were shared with people of the private and public spheres (Lejeune, 2007/2009; McNeill, 2005). Additionally, they can be thought of as a possibility to "write through the seam between the private and the public self” (Serfaty, 2004, p. 29).

The interpretation of the diary form as a dialogue with me, or even a broader imagined audience, is not set for all diaries in the same way; a number of diarists chose a rather intimate form of engagement. They wrote about private relationships and family matters. One diarist even used her private diary and copied and pasted it into my diary after she missed writing entries on two occasions. At the other end of the spectrum were Toomas and Kristjan, who were writing for a large, imagined audience according to their postevaluation after finishing the diary. Rather than treating the diary as a therapeutic or private space for preserving memories, they interpreted the genre as a weblog written to engage with a mainly unknown readership. Toomas was even interested in direct exchange with other writers and readers. He was disappointed when it turned out that the diary entries were not going to be shared with anyone but me.

These kinds of varying interpretations of the diary genre are especially visible in how the diarists started their very first entry. Several participants (Hillar, Alexsandra, and Viktor) started their diaries by addressing me-for example, "Dear Anne"-followed by an introduction of themselves, including a few biographical facts. Others used the common "Dear diary" address in the beginning of every entry, and a third group developed headlines and employed theme-oriented entries (Kajsa, Toomas, and Laine). This broad range of interpreting the diary genre could stand paradigmatically for the constant change of interpretation of expectations by the imagined audience. Genres are never stable entities that can be distinguished from each other in a clear-cut manner. With the Internet, this flexibility and fluidity of the genre understanding has an exponential effect. McNeill (2005) has argued that the borders and characteristics of genres are strongly negotiated; she looks "at the diary's transition from print culture practices in establishing expectations and 'rules' for Weblogs” (p. 2). Hence, established genres are translated from the offline environment into the online and are being renegotiated and redefined based on their position in the online environment. 
Besides the fluidity and flexibility of the online environment contributing to the continuous process of negotiating the diary genre, the threefold relationship between the researcher asking for the diaries, the diarist and the diary as data becomes obvious. The diarists interpret the task of writing the diary differently according to what they think is of interest for the studying researcher. Over time, and by developing a rather intimate relationship with the diary, they partly overcome the feeling of producing valuable content. The decreasing amount of questions directed to me as the researching subject indicated that there was a developing self-certainty and trust and a feeling of not doing something "wrong” among the participants. The introductory words signify a varying perception of implied readership because a number of diarists identified only me as their reader and others appealed to a broader audience. Serfaty (2004) identified similar characteristics of nonsolicited online diaries. She stressed connection, social support, and community building as major functions of online diaries.

\section{Accumulation of information and the advanced possibilities of online diaries}

The online version of diaries has the advantage of extra features that pen-and-paper diaries lack. Several diarists used the online medium to add hyperlinks to music videos mirroring their current emotional situations, upload pictures showing pieces of their everyday lives, and change the interface to adjust it to their aesthetic needs. A number of participants used hyperlinks to illustrate the stories they told in their diaries.

This week in Tartu is the so called student week (www.studentdays.ee/). (Hillar)

With this form of extension of the online diary into a broader public space (e.g., by adding hyperlinks to YouTube or other platforms and publishing the entries on other platforms), the diarist expressed their understanding and interpretation of the relationship between the public and private spheres. Roughly half of the participants seemed to look at the diary as a way to express their opinion about matters of societal or common concern, as well as a way to present their own positions. Many also shared their diary with a broader public. Others seemed to look at the diary as a therapeutic tool for reflecting certain emotional happenings and developments in their lives.

In addition to posting pictures of their rooms, friends, and family or uploading music files and links to YouTube clips, several diarists used emoticons to express certain feelings and emotional conditions. Anu, for example, added an emoticon after nearly every paragraph. In this way, online diaries could also serve as a way to analyze evolving language and sign usage.

\section{Open-endedness and closure}

The diaries written for my study are open-ended in character and closed at the same time. They are open-ended in the sense that diarists were not limited to a certain number of words per entry but could freely expand on topics of interest and freely add external material. In that sense, they were distinct from autobiographical self-representations, which are self-contained forms. At the same time, the narrating process was constrained to a set period of time, namely eight weeks of writing. By putting the weekly (or in some cases daily) entries in chronological order, linearity is constructed; however, the narration is limited to that time frame, too. Diaries are characterized by "stability and motion" (Serfaty, 2004, p. 30). In the entries the diarists presented me, the reader, with their narrated identities, with a worked-out understanding of the self. As such, the entries thus became a space for renegotiating former self-definitions. Temporality was created by linking the diary entries with each other through the presentation of reference points. For example, as illustrated by Alexsandra, 
Next time I would tell you about a party in the student's café, which is going to be that Friday. (Alexsandra)

Last time I told you that I would write about the party in our college. That was now on Friday and we celebrated in honor of the teacher profession. (Alexsandra)

Furthermore, temporality is constructed by narrating past events and by giving future plans: "The two devices_-flashback and foreshadowing — provide both the reader and the writer of diaries with a long-term vision and with a sense of perspective" (Serfaty, 2004, p. 30). Thus, diaries as data present the researcher with a challenging combination of open-endedness and closure of the material.

\section{Challenges}

The main challenge with this type of research is that the diarists must be written language oriented. In the case of the students studied here, the method worked out rather well; however, this end result might be different in less language-oriented groups. Additionally, participants in online diary studies need a certain basic technological knowledge and a thorough introduction to the wiki and how it is used (Sudweeks \& Simhoff, 1999).

Another challenge that should be discussed is that of "digital fatigue." As one of the participants said in the postevaluation, "One gets tired of sitting in front of the computer and of typing." Sudweeks and Simoff (1999) have argued that computer-mediated communication is affected by information and processing overload, which could lead to digital fatigue and avoidance of additional computer-mediated work in form of writing a diary. Because my participants were all students and had a certain load of computer-mediated work already, it is understandable that they were not really keen on spending yet another hour in front of the laptop to write their diary. This processing overload adds to the burden of keeping a diary, even though the participants belong to the so-called "generation of digital natives" (Prensky, 2001, p. 1). Both the written language orientation of diaries and the digital fatigue of the diarist could be overcome by using voice recordings instead of or in addition to written diaries.

In addition to digital fatigue, it is also challenging to secure the confidentiality of the participants. In several cases, they posted pictures of themselves and friends or their homes. This kind of material can be used only under the condition that confidentiality is continuously secure for those directly as well as indirectly involved.

The third challenge is the fact that the diaries are solicited; that is, they were written with the full consciousness of knowing that they were an object of analysis. This approach, of course, has an impact on the choice of topics and what was written about them. Therefore, solicited open-ended diaries must be analyzed differently than nonsolicited diaries published online. At the same time, the act of asking someone to write a diary for the purpose of analysis reveals the way people make sense of their everyday life; for example, they create narrations and construct meanings around events they choose. Additionally, solicited diaries can be focused on a certain topic, as in my case on the role of media and face-to-face discussions with family and friends. In the diaries, the participants reflected on a given topic in connection to various reference points. In the example mentioned earlier, the diarist included reflections on media on an everyday level and how media are embedded in their routines. Others reflected about the role of the media on a metalevel, as Kristjan did: 
My own experience: What I feel is that media is not helping me to fully realize my rights as a citizen, that means that mainstream media is not informative enough. The problem is especially acute, when it comes to in depth analysis of social and political issues. The so-called quality daily newspapers (Postimees, Eesti Päevaleht), which are- - I think —in the position to fill that gap are doing it less and less. (Kristjan)

The high variation and richness of information in the diaries might challenge existing research methods; ultimately, the choice of methods employed in a study should be dictated by the research questions.

\section{Discussion}

Solicited, open-ended diaries provide us with the opportunity to "get close" to the everyday lives of the participants and the periodical form supports the development of an in-depth relationship with the diary. How the diary is written and incorporated into the routines of everyday life could be used to understand the perception and interpretation of the private versus public spheres. Although keeping a diary can be a rather heavy burden for the participants, my diarists developed an intense relationship with their diaries. They present short stories from their everyday lives and relate them to the social and cultural contexts they live in.

Additionally, online research provides researchers with certain advantages. For example, in a group of interest with high internet and computer literacy, an online tool for storing the diaries makes data management and interpretation a great deal easier. The diarists can freely choose when and for how long to write their entries. In addition, they can change the interface, add files or hyperlinks, and thus extend and relate the diary to the "outer world." On the other hand, the online diary is a way for the researcher to keep in contact with the diarists and to keep track of changes and writing intervals. However, the weaknesses of online research must not be underestimated. Here, in particular, I think of ethical and technological challenges, which have to be taken into consideration in every aspect of research planning when using online methods.

Finally, narrative methods give voice to the participants we are interested in. The storytellers are free of time and formal constraints to develop their everyday narrations as they see fit. Through our interpretation of those narrations, we, as researchers, can imagine and potentially understand the everyday lives of our participants. Diaries kept over a longer period also allow for development of a triangular relationship between the diarist, the diary, and the researcher. Regardless, further discussion about online research, diaries as a source of data, and narrative methods is still needed.

\section{Notes}

1. Instructions for the diarists read: "When it comes to the content of the diary, I am generally interested in your everyday life and issues that you find appealing or bothersome. All issues are interesting, from argument with your best friend or parents, to topics which are important for you and which you discuss at school or at home. You are completely free in your reasoning and how to write your dairy. In order to make your writing as easy and comfortable as possible, I formulated keywords that you could keep in mind for your entries. There are no formal requirements. You can choose the language that suits you best: Estonian, Russian, English, etc. I would like to ask you to keep the diaries on a weekly basis over a $\mathbf{2}$ month period (8 weeks - 8 entries). Decide for yourself if you would like to do entries every day or only once per week reflecting your thoughts on the previous seven days. I have created one page for your entries per calendar 
week. You can find them on the upper right side under the link 'pages \& files.' Please post diary entries there. While writing, please keep in mind that I am interested in your thoughts. The good thing about thoughts is they cannot be wrong! In your diaries, I would like you to include some thoughts about the media and how they are influencing your everyday life. List the "thought-stimulators" for everyday life issues, problems that are important for you, your family, public incidents, events that are important for you, your family, public media in your everyday life, what role they play for you and for the issues/events you describe in your diary.”

2. The Estonian society is strongly characterized by segregation between ethnic Estonians and Russians (e.g., they might be Russian or Estonian citizens or stateless). In the latest census, $25.6 \%$ of the population defined themselves as ethnic Russians (Statistics Estonia, 2000).

3. See www.pbwikis.com.

4. See http://pbworks.com/content/security.

5. The first-ever online election was conducted in Estonia on March 4, 2007; see http://www.valitsus.ee/?id=5450.

6. All names used here are randomly chosen pseudonyms.

\section{References}

Banister, P, Burman, E., Parker, I., Taylor, M., \& Tindall, C. (1994). Qualitative methods in psychology: A research guide. Buckingham, UK: Open University Press.

Bennett, S. Maton, K. \& Kervin, L. (2008). The “digital natives” debate: A critical review of the evidence. British Journal of Educational Technology, 39(5), 775-786.

Berger, P. L. \& Luckmann, T. (1991).The social construction of reality: A treatise in the sociology of knowledge. London: Penguin.

Bolger, N., Davis, A. \& Rafaeli, E. (2003). Diary methods: Capturing life as it is lived. Annual Review of Psychology, 54, 579-616.

Booth, T. (1999). Sounds of still voices: Issues in the use of narrative methods with people who have learning difficulties. In A. Bryman \& R. G. Burgess (Eds.), Qualitative research (Vol. 3, pp. 236-252) London: Sage.

Bryman, A. \& Burgess, R. G. (1999). Qualitative research (Vol. 2). London: Sage.

Burgess, R. G. (1999). Keeping a research diary. In A. Bryman \& R.G. Burgess (Eds.), Qualitative research (Vol. 2, pp. 256-262). London: Sage.

Chaitin, J. (2004). My story, my life, my identity. International Journal of Qualitative Methods, 3, 1-15. Retrieved from http://ejournals.library.ualberta.ca/index.php/IJQM/index

Couldry, N., Livingstone, S., \& Markham, T. (2007). Media consumption and public engagement: Beyond the presumption of attention. New York: Palgrave Macmillan. 
Fuchs, C. (2009). Social networking sites and the surveillance society. A critical case study of the usage of studiVZ, Facebook, and MySpace by students in Salzburg in the context of electronic surveillance. Retrieved from http://fuchs.icts.sbg.ac.at/SNS Surveillance Fuchs.pdf

Fry, J., \& Schroeder, R. (2009). Towards a sociology of e-research: Shaping practice and advancing knowledge. In N. W. Jankowski (Ed.), e-Research: Transformation in scholarly practice (pp. 35-53). New York: Routledge.

Genoni, P, Merrick, H., \& Willson, M. (2009). e-Research and scholarly community in the humanities. In N.W. Jankowski (Ed.), e-Research: Transformation in scholarly practice (pp. 91-108). New York: Routledge.

Gershuny, J., \& Sullivan, O. (1998). The sociological uses of time-use diary analysis. European Sociological Review, 14(1), 69-85.

Government of the Republic of Estonia. (2009). E-Estonia. Tallinn: Chancellery of the Republic of Estonia. Retrieved from http://www.valitsus.ee/?id=5450

Habermas, J. (1981).Theorie des kommunikativen Handelns, Band 2: Zur Kritik der funktionalistischen Vernunft. Frankfurt am Main: Suhrkamp Taschenbuch.

Halfpenny, P., Procter, R., Lin, Y., \& Voss, A. (2009). Developing the UK-based e-social science research program. In N. W. Jankowski (Ed.), e-Research: Transformation in scholarly practice (pp. 73-90). New York: Routledge.

Jankowski, N. W. (2009). The contours and challenges of e-research. In N.W. Jankowski (Ed.), eResearch: Transformation in scholarly practice (pp. 3-34). New York: Routledge.

Jones, S. (1999). Studying the net: Intricacies and issues. In S. Jones (Ed.), Doing Internet research: Critical issues and methods for examining the Net (pp. 1-28). Thousand Oaks, CA: Sage.

Kanuka, H., \& Anderson, T. (2007). Ethical issues in qualitative e-learning research. International Journal of Qualitative Methods, 6(2), 20-39. Retrieved from http://ejournals.library.ualberta.ca/index.php/IJQM/index

Kendall, L. (1999). Recontextualizing “cyberspace”: Methodological considerations for on-line research. In: S. Jones (Ed.), Doing Internet research: Critical issues and methods for examining the Net (pp. 57-74). Thousand Oaks, CA: Sage.

Kraut, R., Olson, J., Banaji, M., Bruckmann, A., Cohen, J. \& Couper, M. (2004). Psychological research online: Report of scientific affairs' advisory group on the conduct of research on the Internet. American Psychologist, 59(2), 105-117.

Lejeune, P. (2009). Spiritual journals in France from the sixteenth to the eighteenth centuries (K. Durnin, Trans.). In J. Popkin \& J. Rak (Eds.), On diary (pp. 61-78). Manoa: University of Hawai’i Press. (Original work published 2004)

Lejeune, P. (2009). Counting and managing (K. Durnin, Trans.). In J. Popkin \& J. Rak (Eds.), On diary (pp. 51-60). Manoa: University of Hawai’i Press. (Original work published 2006) 
Lejeune, P. (2009). O my paper! (K. Durnin, Trans.). In J. Popkin \& J. Rak (Eds.), On diary (pp. 93-101). Manoa: University of Hawai’i Press. (Original work published 2007)

Macdonald, C., \& Ounis, I. (2006). The TREC Blogs06 Collection: Creating and Analysing a Blog Test Collection. Retrieved from http://ir.dcs.gla.ac.uk/terrier/publications/macdonald06creating.pdf

McNeill, L. (2005). Genre under construction: The diary on the Internet. Language@Internet, 2. Retrieved from http://www.languageatinternet.de/articles/2005/120

Marwick, A. (2008). LiveJournal users: Passionate, prolific, and private [Report]. Retrieved from http://www.livejournalinc.com/LJ_Research_Report.pdf

Moen, T. (2006). Reflections on the narrative research approach. International Journal of Qualitative Methods, 5(4), 56-69. Retrieved from http://ejournals.library.ualberta.ca/index.php/IJQM/index

Prensky, M. (2001). Digital natives, digital immigrants. Retrieved from http://www.marcprensky.com/writing/Prensky\%20\%20Digital\%20Natives,\%20Digital\%20Immigrants\%20-\%20Part1.pdf

Rak, J. (2009). Dialogue with the truth: Philippe Lejeune's method and theory of diary. In J. Popkin \& J. Rak (Eds.), On diary (pp. 16-26). Manoa: University of Hawai’i Press.

Rautio, P. (2009). Finding the place of the everyday beauty: Correspondence as a method of data collection. International Journal of Qualitative Methods, 8(2) 15-34. Retrieved from http://ejournals.library.ualberta.ca/index.php/IJQM/index

Ritchie, J., \& Lewis, J. (2003). Qualitative research practice: A guide for students and researchers. London: Sage.

Sade-Beck, L. (2004). Internet ethnography: Online and offline. International Journal of Qualitative Methods, 3, 45-51. Retrieved from http://ejournals.library.ualberta.ca/index.php/IJQM/index

Schneider, S. M., Foot, K. A. \& Wouters, P. (2009). Web archiving as e-research. In N. W. Jankowski (Ed.), e-Research: Transformation in scholarly practice (pp. 205-221). New York: Routledge.

Serfaty, V. (2004). The mirror and the veil: An overview of American online diaries and blogs. New York: Rodopi.

Siibak, A. (2009). Self-presentation of the "digital generation” in Estonia. Tartu, Estonia: Tartu University Press.

Statistics Estonia. (2000). Census 2000. Retrieved from http://www.stat.ee/censuses

Sudweeks, F., \& Simoff, S. J. (1999). Complementary explorative data analysis: The reconciliation of quantitative and qualitative principles. In S. Jones (Ed.), Doing Internet research: Critical issues and methods for examining the Net (pp. 29-56). Thousand Oaks, CA: Sage. 
Vilhalemm, P. (2008). Current trends of media use in Estonia. Retrieved from http://www.ceeol.com/aspx/getdocument.aspx?logid=5\&id=e2ebbae166f04174929733e9 $\underline{6813 \mathrm{~d} 5 \mathrm{a} 7}$

Witmer, D. F., Colman, R. W. \& Katzman, S. L. (1999). From paper-and-pencil to screen-andkeyboard: Toward a methodology for survey research on the Internet. In S. Jones (Ed.), Doing internet research: Critical issues and methods for examining the Net (pp. 145161) Thousand Oaks, CA: Sage. 